\title{
Amazônia e Pantanal: mesa-redonda online na socialização do conhecimento para a conservação da biodiversidade
}

\author{
Amazon and Pantanal: online roundtable on knowledge sharing for biodiversity \\ conservation
}

Israel Vítor dos Santos Rodrigues, Laysla Bomfim Adam, Jéssica Prado Silva, Luciana Aguilar-Aleixo*

Universidade Estadual do Sudoeste da Bahia - UESB, Vitória da Conquista, Bahia, Brasil, 45083-900, israelvitor289@gmail.com, http://orcid.org/0000-0001-7411-5650; 1aysla.adam@,hotmail.com, http://orcid.org/0000-0003-3148-4645; jessica.pradosilva@hotmail.com, http://orcid.org/0000-00033524-8009; "1ucianaaleixo@uesb.edu.br, http://orcid.org/0000-0003-0728-6163 (autora correspondente)

\section{Resumo}

Diante do cenário de pandemia que vivenciamos, o conceito de "Saúde Única" ganhou força para a promoção de um meio ambiente saudável e equilibrado, garantindo acesso aos recursos para as gerações presente e futura. Para que a população esteja informada é necessária a divulgação científica acessível e desmistificada. Os eventos online, como as mesas-redondas promovidas pelo projeto de extensão "Evolução Para Todos" levam o conhecimento de temas atuais à luz da evolução para a população. A mesa-redonda "Amazônia e Pantanal: compreendo a coevolução a partir desses biomas", teve como objetivo expor e debater a importância desses biomas e as problemáticas que envolvem as ações antrópicas, como o desmatamento e consequentes queimadas. $\mathrm{O}$ evento foi utilizado como fonte para esta pesquisa qualitativa descritiva, na forma de pesquisa-ação. Os convidados expuseram o cenário atual de perda de biodiversidade com base em pesquisas realizadas por eles e por outros cientistas. Ao final ocorreu um importante debate, esclarecendo dúvidas dos ouvintes. Feedback positivo foi obtido por meio dos comentários realizados via chat, mostrando que o evento somou conhecimento, despertando nos participantes a visão integrada entre saúde animal, humana e ambiental, e a necessidade de ação conjunta em prol do uso sustentável dos recursos naturais. 
Palavras chave: biomas brasileiros, divulgação científica, pandemia, saúde única.

\begin{abstract}
In the face of the pandemic scenario that we are experiencing, the concept of "One Health" gained strength to promote a healthy and balanced environment, ensuring access to resources for present and future generations. For the population to be informed, accessible and demystified scientific dissemination is necessary. Online events, such as roundtables promoted by "Evolução para Todos" (Evolution for Everyone) extension project, bring knowledge of current issues in the light of evolution for the population. The roundtable "Amazon and Pantanal: understanding coevolution from these biomes", aimed to expose and debate the importance of these biomes and the issues surrounding anthropic actions, such as deforestation and consequent fires. The event was used as a source for this descriptive qualitative research, in the form of action research. The guests explained the current scenario of biodiversity loss based on research conducted by them and other scientists. At the end there was an important debate, clarifying the doubts of the listeners. Positive feedback was obtained through comments made via chat, showing that the event added knowledge, awakening in the participants an integrated vision between animal, human, and environmental health, and the need for joint action for the sustainable use of natural resources.
\end{abstract}

Keywords: Brazilian biomes, scientific dissemination, pandemic, one health.

\title{
1. Introdução
}

A Saúde Única ou One Health é um conceito em ascensão que busca unir aspectos da saúde humana, animal e ambiental, a fim de esclarecer a coligação da saúde humana, e da saúde animal ao ecossistema no qual estes estão inseridos, objetivando a promoção de práticas de saúde coletiva nos centros urbanos (Lima et al., 2020).

Nessa abordagem, existem alguns fatores que influenciam na condição sanitária de uma localidade, como as questões sociais, os aspectos econômicos e comportamentais e o ambiente. Essa visão integrada gera o entendimento de que a saúde humana, bem como seu estado sanitário, está relacionada com a saúde dos animais, e que ambos afetam e são afetados de forma equivalente pelo ambiente. A Saúde Única tem entre suas premissas a abordagem multiprofissional e colaborações interdisciplinares, visando os cuidados com a saúde, amplamente, para seres humanos, animais e meio ambiente (Limongi \& Oliveira, 2020).

Para que os fins da Saúde Única sejam alcançados, são necessárias políticas públicas visando a prevenção, vigilância, biossegurança, biocontrole e tratamento de enfermidades. Em complemento, ou quase que simultaneamente a isso, se fazem necessárias ações que busquem empregar e propagar informações e conhecimentos ligados a zoonoses, favorecendo a manutenção da saúde e de um ambiente mais equilibrado (Lima et al., 2020). Priorizar esse tipo 
de estudo é realizar a vigilância e organizar estratégias para prevenção de problemas, tentando

dessa forma reduzir o número de mortes de pessoas, animais, e o agravamento da situação do planeta (Mothé et al., 2020).

A compreensão de cada esfera dessa triunidade é o pilar para sua efetivação. As esferas da saúde humana e da saúde animal estão ambas inseridas na ampla esfera do meio ambiente. $\mathrm{O}$ meio ambiente inclui os elementos bióticos e abióticos, organizados nos ecossistemas nos quais o ser humano se insere, em interações que atendem ao desenvolvimento humano, e à preservação dos recursos naturais e das características ao seu redor (Coimbra 2002, apud Pereira; Curi, 2012). Em virtude do que foi mencionado, o contexto de Saúde Única está inserido no meio ambiente. Dentro desses elementos e ecossistemas se encontram áreas geográficas reguladas e caracterizadas por diversos fatores, como o macroclima, solo, e também a fauna e a flora. Essas áreas são denominadas biomas.

A palavra bioma vem do grego Bio que significa vida e Oma, que corresponde a um grupo ou massa (Colinvaux, 1993). Bioma se refere não apenas à vegetação, mas ao conjunto de vegetação e fauna, se caracterizando pela uniformidade da fisionomia vegetal e pelos animais majoritariamente relevantes, tendo assim uma composição biótica característica (Coutinho, 2006). Dentre os biomas brasileiros, Amazônia e Pantanal recebem grande destaque nacional e internacional pela sua riqueza e beleza, embora sejam drasticamente impactados pela ação antrópica.

Amazônia é uma floresta latifoliada úmida que cobre a maior parte da América do Sul, e abriga a maior biodiversidade do planeta. O bioma florestal da Amazônia é um dos maiores tesouros biológicos da Terra (Malhi et al., 2008). Considerada a região ideal para o reconhecimento de ecossistemas existentes em um determinado território (Tansley \& Chipp, 1926), perpassa por nove países, com uma área territorial de aproximadamente 5,5 milhões de $\mathrm{km}^{2}$. A maioria da Amazônia está contida no Brasil, que detém 60\% da floresta, abrangendo $58,9 \%$ do território brasileiro (IBGE, 2020).

O Pantanal, uma das maiores planícies alagadas do mundo, é o menor bioma em extensão territorial do país. Sua área de aproximadamente $150.000 \mathrm{~km}^{2}$ está localizada nos estados do Mato Grosso e Mato Grosso do Sul, e se estende além da fronteira brasileira, no norte do Paraguai e no leste da Bolívia. Declarado "Patrimônio Natural da Humanidade" pela UNESCO, o Pantanal e a sua mistura de habitats permanentes e temporariamente alagados, com matas de 
galeria ou manchas, contribuem para a riqueza da vegetação e produtividade do sistema, que

por sua vez, sustenta uma exuberante abundância faunística (Alho, 2008).

O desmatamento desses biomas se torna um motor para as mudanças climáticas, que acarretam consequências negativas para o ambiente. Em 2019, a Amazônia registrou as maiores taxas de desmatamento da última década, e segundo dados apresentados no Programa de Queimadas do Instituto Nacional de Pesquisas Espaciais (INPE, 2020), o Pantanal apresentou o maior número de queimadas registrado em 22 anos. A interação da pandemia pela COVID19, causada pelo vírus SARS-CoV-2, e as queimadas na Amazônia e no Pantanal, intensificaram os riscos à saúde das diferentes populações que vivem nessas áreas, visto que a fumaça gerada pelas queimadas tem o potencial de aumentar o impacto de um surto de COVID-19 em aproximadamente 10\% (Henderson, 2020).

Além disso, um dos problemas de saúde pública mais recorrentes são as zoonoses, e muitas delas advêm dos biomas aqui citados, Amazônia e Pantanal. Um exemplo disso é a leptospirose bovina, doença endêmica muito frequente em países da região tropical, tendo sua prevalência maior na região Centro-Oeste do Brasil, onde se localiza o Pantanal. É uma doença que tem como hospedeiro intermediário o bovino, mas é o ser humano o último hospedeiro da cadeia de transmissão, por contato com sangue, tecidos, urina, solo ou água contaminados (Jamas et al., 2020). Sendo assim a leptospirose se encaixa no contexto da Saúde Única, de forma que o animal é afetado, o ser humano também, e o meio ambiente atua como gerente do agente infeccioso, formando-se assim a tríade que caracteriza a Saúde Única, necessitando também do multiprofissionalismo presente na mesma para o combate à sua disseminação.

Desmatamento, queimadas e aumento de zoonoses são reflexos dos impactos das ações humanas nos biomas, afetando de forma direta ou indireta, os três pilares da Saúde Única. Visando a diminuição desses impactos e a conscientização da sua magnitude, o meio científico tem utilizado ferramentas e alternativas para que os conhecimentos atinjam o maior número de pessoas. Assim têm surgido e ganhado forças, projetos e eventos de extensão, com o intuito de popularizar e disseminar a ciência para pessoas de fora da esfera acadêmica, embora este ainda seja um caminho longo e árduo a ser trilhado.

Um dos grandes desafios da ciência é a sua popularização, uma vez que o conhecimento produzido pelas instituições e pesquisadores costumam se restringir a este meio, de tal forma que a população, que mais precisa dessas informações, acaba sendo excluída. A dificuldade de 
popularização da ciência no Brasil, decorre dos altos índices de pobreza e escolaridade da

população, que interferem diretamente no acesso e compreensão do conhecimento (Nunes et al., 2020). Um dos mecanismos que poderiam facilitar a intermediação entre o âmbito acadêmico e o popular são as Tecnologias Digitais de Informação e Comunicação (TDICs). Além disso, outro inimigo além da falta de informação são as notícias falsas. Castelfranchi (2018), recomenda o aumento da alfabetização informacional, com uso de fontes confiáveis e de ferramentas para ajudar no combate à desinformação. As mídias sociais entram como um importante meio de popularizar e disseminar o conhecimento científico, por meio de linguagem acessível e atraente, com o uso de imagens chamativas, abordagem de temas que incitam a curiosidade ou a polêmica, mas que, simultaneamente, também precisam de um esclarecimento.

Diante do cenário exposto, a equipe do projeto de extensão Evolução Para Todos realizou uma mesa-redonda online a fim de expor a importância da Amazônia e Pantanal, com ênfase ao impacto das ações antrópicas em escala nacional, buscando levar esse assunto para um público o mais diversificado possível.

\section{Material e Métodos}

No contexto da pandemia por COVID-19, o afastamento social necessário para evitar a disseminação do vírus favoreceu a realização de eventos online. A mesa-redonda ocorreu no dia oito de outubro de 2020 e contou com 180 ouvintes certificados. Atualmente já ultrapassou 900 visualizações no canal da TV UESB e 53 no canal do Evolução Para Todos (última atualização em primeiro de novembro de 2021) permanecendo disponível nos canais do Youtube @tvuesb e @evolucaoparatodos, através do link: https://youtu.be/I2yW-DgIEGU. O evento contou com dois profissionais convidados, uma especialista no bioma Amazônia, a Professora Dr. ${ }^{\text {a }}$ Karine Santana Carvalho (C1) e outro no bioma Pantanal, o Professor Dr. Fernando Henrique M. Gonçalves (C2). Contou também com a participação de dois mediadores integrantes do projeto, a professora Dr. ${ }^{a}$ Raquel Pérez Maluf (M1) e o professor Dr. Raymundo José de Sá Neto (M2), que contextualizaram o tema e conduziram a mesa-redonda, contribuindo para a realização de um importante debate ao final das apresentações. 
O trabalho utilizou-se de uma pesquisa aplicada com abordagem qualitativa e descritiva do tipo pesquisa-ação, com coleta de dados através da observação do participante (ouvinte) a fala dos palestrantes e o debate proporcionado.

Os resultados foram avaliados a partir da interpretação dos atores (palestrantes e ouvintes) da live como método educativo e de compartilhamento de conhecimentos entre os palestrantes, os mediadores e os ouvintes de forma interdisciplinar, trazendo um contexto amplo e formativo acerca do tema (Neves et al. 2021).

\section{Resultados}

No início do mês de outubro são comemorados os dias da abelha, da natureza e dos animais e o dia mundial das aves. Além disso, era um momento delicado em que tanto a Amazônia quanto o Pantanal vinham sofrendo queimadas constantes. Em comemoração a essas datas realizamos a mesa-redonda abrangendo estes dois importantes biomas e as problemáticas que vêm colocando sua biodiversidade em situação de vulnerabilidade.

A convidada $\mathrm{C} 1$ começou sua fala pontuando a complexidade da Amazônia, que detém de 10 a $15 \%$ da biodiversidade do planeta, sendo a principal fonte de água doce do mundo, que regula os ciclos hidrológicos e os padrões climáticos de toda a América do Sul.

Em seguida ela focou nas interações ecológicas mais exploradas nos estudos de coevolução, que são as interações inseto-planta. Os insetos têm a maior diversidade e abundância na Terra, apresentando por isso tantas interações com as plantas. Essa diversidade genética possibilitou a adaptação a diversas partes do planeta, com maior concentração nos trópicos.

Como produtoras primárias, as plantas, por sua vez, são a base dos ecossistemas florestais. As plantas vasculares com sementes surgiram na era paleozoica há aproximadamente 350 milhões de anos. Todos os processos de interação entre insetos e plantas são extremamente antigos, tendo surgido logo após a irradiação das plantas vasculares com sementes. A polinização e a dispersão garantem a movimentação das plantas no espaço, e a migração de genes entre populações.

Visando linkar polinização e dispersão de sementes ao desmatamento e queimadas, há um consenso de que esta destruição da floresta, com abertura de novas áreas para pastagens e agronegócio, está reduzindo a diversidade de polinizadores, especialmente de abelhas. O nicho 
das abelhas está diminuindo e com o declínio desses polinizadores nos próximos 100 anos, irá faltar alimento no mundo.

O convidado $\mathrm{C} 2$ discorreu um pouco sobre o seu trabalho que envolve vertebrados antófilos, "amigos das flores", os morcegos que polinizam plantas. A partir de trabalhos

realizados mostrou que áreas desmatadas perdem a diversidade de espécies de morcegos e consequentemente de serviços ecossistêmicos. Quando se perde uma espécie de planta ou uma espécie de polinizador ou dispersor, perde-se anos de história evolutiva, que foram ao longo do tempo se especializando, principalmente na Amazônia que é um bioma antigo onde a pressão evolutiva é muito grande.

Ambos chamaram a atenção às consequências do desmatamento e das queimadas nas relações coevolutivas: declínio dos polinizadores, com consequentes prejuízos na produção de alimentos. É premente a mudança no tratamento de nossos biomas. Além disso, um alerta é a savanização dos biomas em decorrência do fogo, com espécies invasoras que passam a ocupar os espaços abertos pelo fogo, sem contribuir para a manutenção dos serviços ecossistêmicos, gerando esse novo cenário. Ações antropogênicas têm uma pressão grande nas relações coevolutivas, já que estas se estabelecem ao longo de milhares de anos. Desmatamentos e queimadas ao eliminarem plantas irão comprometer também seus polinizadores. Quanto mais espécie-específicas forem as relações, mais vulneráveis serão os organismos envolvidos. Redes de interação muito especializadas serão mais prejudicadas com a perda de uma espécie.

Antes do início das palestras os participantes foram convidados a interagir em uma nuvem de palavras na plataforma online Mentimeter. Esta primeira interação identificou o que associavam à coevolução (figura 1a). A maioria indicou a evolução simultânea, interação e adaptação. Os palestrantes destacaram que os ouvintes teriam compreendido bem as falas, já que a coevolução foi a interação chave nas apresentações, com foco especial às interações entre insetos e morcegos, animais polinizadores e as angiospermas.

Após o término das palestras, perguntou-se que palavras as palestras associam com a conservação da biodiversidade (figura 1b). A partir desta segunda nuvem de palavras, pode-se perceber que os ouvintes se apropriaram de conhecimentos compartilhados nas palestras, já que muitos citaram sustentabilidade, antropoceno, educação ambiental, conservação e saúde. 


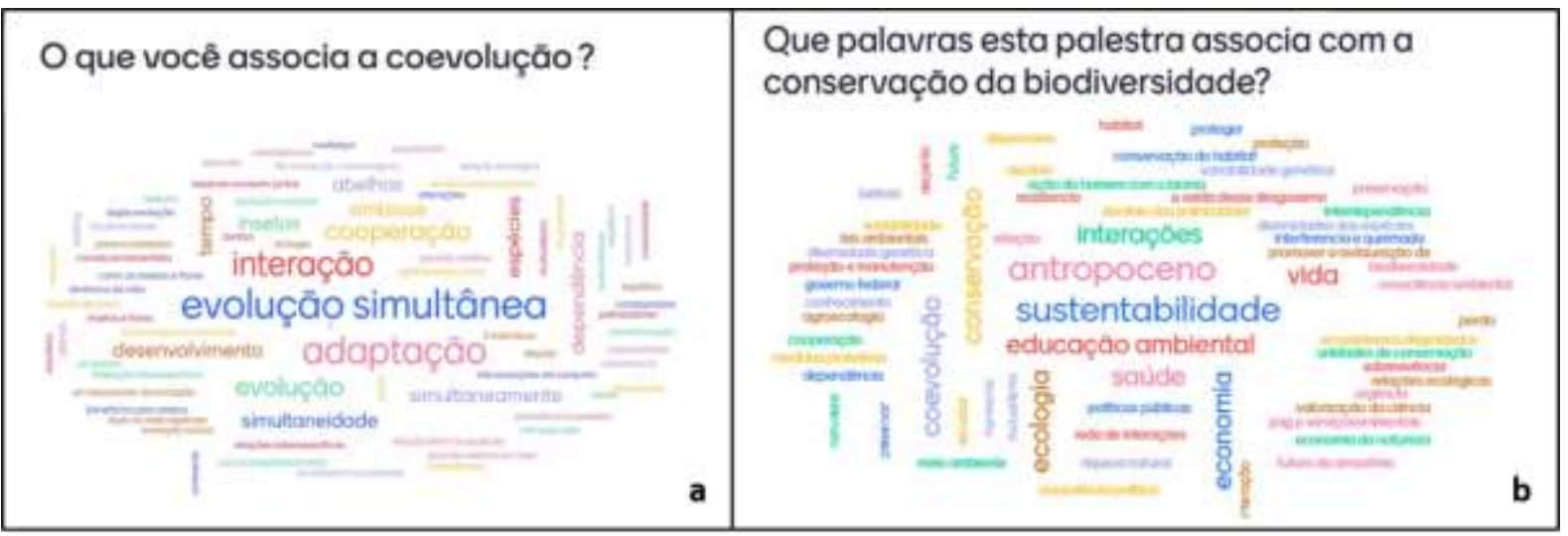

Figura 1. Nuvens de palavras produzidas pela interação dos ouvintes da mesa-redonda na plataforma online Mentimeter. a- Palavras associadas à coevolução; b- Palavras associadas à conservação da Biodiversidade.

O debate é o ponto chave da mesa-redonda, sanando os questionamentos despertados ao longo das palestras. Algumas perguntas realizadas via chat e respondidas pelos convidados mostram o interesse dos participantes, com destaque às seguintes:

Ouvinte 1: "Essas queimadas indiscriminadas podem afetar essas interações tão bonitas? É pior que o desmatamento sem fogo?"

Ouvinte 2: “Como entender a relação entre conservação e economia? É possível um diálogo e resultado efetivo?"

Estas e outras perguntas promoveram um importante debate. Como feedback positivo em relação à importância das mídias sociais na popularização e disseminação do conhecimento científico durante a mesa-redonda, alguns ouvintes escreveram:

Ouvinte 3: "As lives estão possibilitando a gente conhecer e interagir com profissionais ótimos além da nossa universidade. Estou amando esse lado positivo da vida online."

Ouvinte 4: "Esclarecidas algumas importantíssimas questões! Parabéns aos envolvidos!" 
Ouvinte 5: "Muito boas as apresentações e discussões. Parabéns a todos envolvidos e organizadores!"

Ouvinte 6: "Excelentes palestras e discussões! Parabéns@Evolução Para Todos e aos palestrantes, super necessária essa mesa redonda!"

\section{Discussão}

As ações antrópicas estão impactando diretamente a saúde animal e humana, e obviamente o meio ambiente. No Brasil, um dos principais problemas ambientais, que afeta também a saúde global, é o incêndio florestal, que ocorre principalmente nos biomas do Pantanal e da Amazônia. Em relação a isso, os estados do Pará, Amazonas e Mato Grosso do Sul foram os que apresentaram o maior número de focos de fogo em agosto de 2020, e continuaram a liderar por todo o ano.

Segundo o INPE (2020), a Amazônia registrou mais pontos de calor, porém o Pantanal foi o mais afetado pela sua relação de área. Esse problema se caracteriza por uma invasão descontrolada do fogo, que acaba por destruir qualquer tipo de vegetação. Esse fogo pode surgir por forças naturais, mas na maioria das vezes é fruto de ação antrópica, constituindo um crime. As denominadas queimadas controladas, usadas para fins agrícolas e pastoris, utilizam o fogo de maneira controlada, para "limpar e renovar" a pastagem. Entretanto, seja natural ou proposital, representam uma ameaça à biodiversidade e perturbam o equilíbrio ecológico, pois além da destruição causada à fauna e flora ainda ocasiona a poluição (White et al., 2013; Mothé et al., 2020).

De acordo a Angelotti et al. (2017), esses incêndios afetam também a saúde humana pela fumaça produzida, além do fato de que muitos medicamentos são fabricados por extração de substâncias da fauna e da flora, que por vez são destruídas pela ação do fogo, atrasando ou cessando o progresso terapêutico. Segundo Santos et al. (2015), mesmo que os animais sobrevivam à ação das queimadas, com a perda de seu habitat vem também a perda da qualidade de vida, resultando na migração em busca de lugar para habitar e se alimentar. Nesta busca acabam muitas vezes sendo atropelados, caçados ou morrendo de fome. Assim, os incêndios são uma ameaça consistente no que se diz respeito ao processo de extinção de diversas espécies (Angelotti et al., 2017). 
Uma palestrante chamou a atenção para as ações antrópicas e o quão nociva é a visão antropocentrista. Diante disso, o mediador complementou: "Saúde Única mostra que sem o ambiente saudável, sem a biodiversidade, a saúde fica cara e para poucos, então hoje, esse momento que a gente vive nessa pandemia, a gente está percebendo mais o quanto a gente precisa da natureza."

Aproximar a sociedade do conhecimento acadêmico torna-se ainda mais importante diante do cenário de pandemia e destruição dos habitats que está ocorrendo (Aguilar-Aleixo \& Marisco, 2020). Segundo Oliveira (2018), a divulgação cumpre a função primordial de democratizar o acesso ao conhecimento e dar condições para a denominada alfabetização científica, voltada para o público leigo.

Em um projeto realizado em uma escola pública de São Luís-MA, verificou que apenas 10\% dos alunos sabiam o que são zoonoses (Silva et al., 2021). A má informação em saúde única pode gerar graves consequências, sendo a principal delas a ausência de saúde, o não cuidado com o meio ambiente e os maus tratos com os animais. Dados como esse ressaltam a importância da divulgação científica desmistificada e acessível para todos. Com base nisso é imprescindível a formação dos educadores sobre saúde única, uma vez que a preparação adequada sobre o tema pode contribuir substancialmente para a promoção da Saúde Única (Seixas et al., 2017).

A busca pela popularização do saber científico se soma na formação acadêmica dos alunos extensionistas, proporcionando a consolidação do conhecimento adquirido durante o curso. As ações extensionistas são pontes de diálogo importantes para a compreensão da saúde única como pilar visando o bem-estar do meio ambiente e da sociedade (Aguilar-Aleixo \& Marisco, 2020).

Reconhecer a interconectividade entre a sociedade, os animais domésticos e silvestres e o meio ambiente é garantir a efetivação da saúde única (Gebreyes et al., 2014). O cenário pandêmico que a humanidade vivencia é um alerta para a necessidade de mudanças na forma como se produz e consome. Novas formas de se relacionar com o meio, mais sustentáveis, são essenciais (Rabelho \& Oliveira, 2020), reafirmando a importância da aplicação do conceito de saúde única bem como a capacitação de profissionais e a promoção interdisciplinar do acesso às informações (Limongi \& Oliveira, 2020). 
Eventos online por si só não são capazes de substituir a aula teórica e todo o saber adquirido ao longo das disciplinas, mas podem contribuir de forma substancial para um ensinoaprendizagem mais dinâmico. As mesas-redondas virtuais possuem a vantagem de promover a interação de diferentes públicos de várias localidades, o que seria inviável no formato presencial, devido aos custos de deslocamento (Aguilar-Aleixo; Marisco, 2020).

A utilização das mídias digitais tornou-se uma grande aliada no processo de divulgação dos conteúdos produzidos na universidade para a sociedade (Oliveira \& Mattar-Neto, 2018). Quando vinculadas de forma acessível, as mídias constituem-se um forte elo entre o público e a ciência (Fraga \& Rosa, 2015).

\section{Agradecimentos}

Agradecemos primeiramente à equipe do projeto "Evolução Para Todos", aos pesquisadores convidados e ao público pela participação e envolvimento com o evento. Agradecemos também à UESB por conferir credibilidade ao projeto disponibilizando o canal da TV UESB no YouTube, divulgando nossas ações via site e correio eletrônico.

Por fim agradecemos à Pró-reitoria de Extensão (PROEX/UESB) pela concessão das bolsas de extensão, financiadas pela UESB, a dois dos autores.

\section{Referências}

Aguilar-Aleixo, L. \& Marisco, G. (2020). O diálogo universidade-sociedade promovido por projetos de extensão em Evolução, Saúde e Biodiversidade utilizando TDICs. Revista Extensão \& Cidadania, v. 8, n. 14, p. 447-459. https://doi.org/10.22481/recuesb.v8i14.7847

Alho, C. J. R. (2008). Biodiversity of the Pantanal: response to seasonal flooding regime and to environmental degradation. Brazilian Journal of Biology, v. 68, p. 957-966. https://doi.org/10.1590/S1519-69842008000500005

Angelotti, F.; Ghini, R.; Bettiol, W. (2017). Como o aumento da temperatura interfere nas doenças de plantas? In: Bettiol, W.; Hamada, E.; Angelotti, F. et al. (orgs.). Aquecimento global e problemas fitossanitários. Brasília, DF: Embrapa, p. 116-143.

Castelfranchi, Y. (2018). Notícias falsas na ciência. Revista Ciência Hoje. Disponível em:

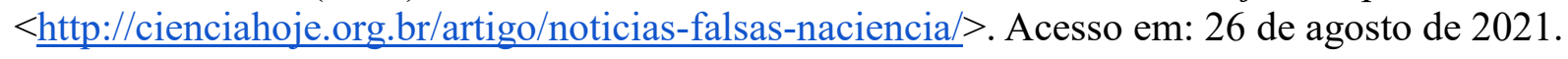

Colinvaux, P. (1993). Ecology. $2^{\text {a }}$ ed. New York, John Wiley \& Sons,Inc. 744p. 
Coutinho, L. M. (2006). O conceito de bioma. Acta Botanica Brasilica. v. 20, n. 1, p. 13-23. https://doi.org/10.1590/S0102-33062006000100002

Fraga, F. B. F. F; Rosa, R. T. D. (2015). Microbiologia na revista Ciência Hoje das Crianças: análise de textos de divulgação científica. Ciência \& Educação, v. 21, n. 1, p.199-218. https://doi.org/10.1590/1516-731320150010013

Gebreyes, W. A.; Camet-Dupouy, J.; Newport, M. J. et al. (2014). The global One Health paradigm: challenges and opportunities for tackling infectious diseases at the human, animal, and environment interface in low-resource settings. PLoS neglected tropical diseases, v. 8, n. 11, p. e3257. https://doi.org/10.1371/journal.pntd.0003257

Henderson, S. B. (2020). The Covid-19 pandemic and wildfire smoke: potentially concomitant disasters. American Journal of Public Health. v. 110, p. 1140-1142. https://doi.org/10.2105/AJPH.2020.305744

IBGE - Instituto Brasileiro de Geografia e Estatística. (2020). Amazônia Legal. Disponível em: www.ibge.gov.br/geociencias/cartas-e-mapas/mapas-regionais. Acesso em 25 de agosto de 2021.

INPE - Instituto Nacional de Pesquisas Espaciais. (2020). Programa Queimadas. Disponível em: https://queimadas.dgi.inpe.br/queimadas. Acesso em 25 de agosto de 2021.

Jamas, L. T., Barcellos, R. R., Menozzi, B. D. et al. (2020) "Leptospirose bovina", Veterinária e Zootecnia. Botucatu, v. 27, p. 1-19. https://doi.org/10.35172/rvz.2020.v27.403

Lima, N. T. S.; Araujo, L. R. T.; Araujo, B. V. S. et al. (2020). Unique Health from the perspective of popular health education. Research, Society and Development, [S. 1.], v. 9, n. 10, p. e8839109314. https://doi.org/10.33448/rsd-v9i10.9314

Limongi, J. E \& Oliveira, S. V. (2020). COVID-19 e a abordagem One Health (Saúde Única): uma revisão sistemática. Vigilância Sanitária em Debate, v. 8, n. 3, p. 139-149. https://doi.org/10.22239/2317-269X.01610

Malhi, Y.; Roberts, J. T.; Betts, R. A. et al. (2008). Climate change, deforestation, and the fate of the Amazon. Science, v. 319, n. 5860, p. 169-172. https://doi.org/10.1126/science.1146961

Mothé, R.; Siqueira, J.; Mendes-Junior, A. et al. (2020). One Health pela perspectiva da saúde ambiental: incêndios florestais. Enciclopédia biosfera, v. 17, n. 34, p 369-383. https://doi.org/10.18677/EnciBio_2020D28

Neves, V. N. S. et al. Utilização de lives como ferramenta de educação em saúde durante a pandemia pela COVID-19. Educação \& Sociedade, v. 42, p. 1-17, 2021. https://doi.org/10.33448/rsd-v10i12.20360

Nunes, M. S. C.; Veloso, R. M. P.; Fernandes-Junior, P. R. et al. (2020) A popularização da ciência e a disseminação da informação científica. ConCI: Convergências em Ciência da Informação, v. 2, n. 3, p. 171-198. https://doi.org/10.33467/conci.v2i3.13718 
Oliveira, N. A. A. \& Mattar-Neto, J. A. (2018). Folhetim Lorenianas: aprendizagem baseada em projetos, pesquisa e inovação responsáveis na educação. Revista e-Curriculum, v. 16, n. 2 , p. 341-363. https://doi.org/10.23925/1809-3876.2018v16i2p341-363

Oliveira, T. M. (2018). Midiatização da ciência: reconfiguração do paradigma da comunicação científica e do trabalho acadêmico na era digital. Matriz, v. 12, n. 3, p. 101-126. https://doi.org/10.11606/issn.1982-8160.v12i3p101-126

Pereira, S. S. \& Curi, R. C. (2012). Meio ambiente, Impacto ambiental e Desenvolvimento Sustentável: Conceituações Teóricas sobre o Despertar da Consciência Ambiental. REUNIR: Revista de Administração Contabilidade e Sustentabilidade, v. 2, n. 4, p.35-57. https://doi.org/10.18696/reunir.v2i4.78

Rabelho, A. M. \& Oliveira, D. B. (2020). Impactos ambientais antrópicos e o surgimento de pandemias. Unifesspa: Painel Reflexão em tempos de crise, v. 26.

Santos, W. de S.; Souto, P. C.; Souto, J. S. et al. (2015). Estimativa dos riscos de ocorrência de incêndios florestais no Parque Estadual Pico do Jabre, na Paraíba. Agropecuária Científica do Semiárido, Patos, v. 11, n. 1, p. 80-84. http://dx.doi.org/10.30969/acsa.v11i1.649

Seixas, M. M.; Nery, G.; Souza, E. P. et al. Formação de educadores para promoção da saúde única em distrito sanitário de Salvador: estudo piloto. Revista Baiana de Saúde Pública, v. 41, n. 2, 2017. https://doi.org/10.22278/2318-2660.2017.v41.n2.a2383

Silva, F. R.; Sá, K. B. M.; Garcês, A. R. C. et al. Educando para o bem estar animal e a saúde única. Revista Práticas em Extensão São Luís, v. 5, n. 01, p. 820-931, 2021.

Tansley, A. G. \& Chipp, T. F. (1926). Aims and methods in the study of vegetation. $1^{\text {a }}$ ed. London: British Empire Vegetation Committee, 383p.

White, B. L. A.; White, L. A. S.; Ribeiro, G. T. et al. (2013). Development of a fire danger index for Eucalypt plantations in the northern coast of Bahia, Brazil. Floresta, v. 43, n. 4, p. 601-610. http://doi.org/10.5380/rf.v43i4.30973

\section{Direitos autorais (Copyrights)}

Financiamento: Esta pesquisa não recebeu nenhum financiamento

Conflitos de interesse: Os autores declaram não haver conflitos de interesse Aprovação do comitê de ética: Não aplicável

Disponibilidade dos dados de pesquisa: Todos os dados gerados ou analisados neste estudo estão incluídos no manuscrito. A transmissão da mesa-redonda pode ser conferida no endereço eletrônico: https://youtu.be/I2yW-DgIEGU

Contribuição dos autores: Os autores contribuíram equitativamente na construção do artigo. 